\title{
Effect of Partial Urethral Obstruction on Force Development of the Guinea Pig Bladder
}

\author{
Gommert A. van Koeveringe, Jacek L. Mostwin, Ron van Mastrigt, and \\ Bram J. van Koeveringe
}

James Buchanan Brady Urological Institute, Johns Hopkins Medical Institutions, Baltimore, Maryland (G.A.V.K., J.L.M.); Department of Urology, Division of Urodynamics, Erasmus University Rotterdam, Rotterdam, The Netherlands (G.A.V.K., R.V.M., B.J.V.K)

\begin{abstract}
We created gradual partial urethral obstruction in 20 guinea pigs using silver jeweler's jump rings. After 4 or 8 weeks obstruction all animals underwent cystometry and were assigned to one of five urodynamic categories: normal, high pressure voiding, unstable, low compliance, or decompensated. After sacrifice, the contractile responses of bladder strips to electrical field stimulation of intramural nerves, direct electrical muscle stimulation, $0.1 \mathrm{mM}$ carbachol, and high $\mathrm{K}+$ solution were sampled by computer for phase plot analysis. Following 8 weeks obstruction, the value of the phase plot parameter Fiso, indicative of the number of contractile muscle units, was reduced to $60 \%$ of the control response to nerve stimulation $(P<0.05)$ and to $77 \%$ of the control response to carbachol stimulation $(P<0.05)$. Parameter $\mathrm{C}$, the slope of the phase plot (indicative of unit recruitment during force development), was unchanged for all forms of stimulation. Although in the latter case not statistically significant, obstruction affected responses to nerve and muscle stimulation similarly suggesting that muscle change may possibly be a common denominator of dysfunction. In view of the reduction in Fiso and the increase in bladder weight, instability may represent a more advanced form of dysfunction due to obstruction than high pressure voiding. 1993 Wiley-Liss, Inc.
\end{abstract}

Key words: muscle contraction, urethral obstruction, smooth muscle, urodynamics

\section{INTRODUCTION}

A model for urethral obstruction in male albino guinea pigs was developed at Johns Hopkins University, Baltimore [Mostwin and Brooks, 1989; Mostwin et al., 1991]. The aim of this study was to investigate the changes in functional properties of the detrusor muscle tissue after a period of partial urethral obstruction. Changes in bladder contractility, whether or not combined with instability, have been demonstrated by numerous clinical observations in man suffering from enlargement of the prostate [Blaivas, 1988; Coolsaet and Blok, 1986]. The guinea pig model served to

Received for publication June 25, 1992; accepted May 1, 1993.

Address reprint requests to Gommert A. van Koeveringe, Department of Urology, Division of Urodynamics, Room EE 1630, Erasmus University Rotterdam, P.O. Box 1738, 3000 DR Rotterdam, The Netherlands. 
investigate both in vivo urodynamic properties and the in vitro detrusor muscle contractility. In organ bath studies detrusor muscle contractility had been investigated previously at the Erasmus University Rotterdam, The Netherlands, by means of phase plot analysis [Van Mastrigt et al., 1986; Van Mastrigt and Glerum, 1985]. This method describes muscle force development by means of two parameter values, one of these representing a time constant [Van Koeveringe and Van Mastrigt, 1991]. In order to relate in vitro to in vivo changes, we studied changes in phase plot parameter values after different time periods or in different categories of post-obstructive urodynamic dysfunction. Many previous studies on in vitro smooth muscle contractility concentrated on maximum developed force or pressure only [Brading and Sibley, 1983; Malkowicz et al., 1986; Mattiasson and Uvelius, 1982]. Besides the maximum generated force, this study also investigated the time dimension in the force development.

\section{MATERIALS AND METHODS Operation}

Partial urethral obstruction was created in 20 immature albino guinea pigs (Hartley strain) weighing 250-350 g using jeweler's jump rings (2.2 mm i.d.) according to the method we have previously described [Mostwin et al., 1991]. After anesthesia with intraperitoneal (i.p.) sodium pentobarbital $(40 \mathrm{mg} / \mathrm{kg}$ ), the peritoneal cavity was entered through a low vertical midline abdominal incision and the bladder was identified. It was drained of urine by syringe and a monofilament nylon suture was placed through the bladder for traction. The delicate connective tissue anterior to the bladder neck was identified and opened with scissors. The loose areolar tissue beneath this layer was separated carefully without cutting to avoid injury to small blood vessels in this space. These vessels are friable, bleed easily, and may possibly contribute to excessive perivesical fibrosis during healing. In this manner the bladder neck and proximal urethra were exposed. Without further dissection, a silver jeweler's jump ring ( $2.2 \mathrm{~mm}$ internal diameter) was twisted open and passed around the proximal urethra without damaging the web of connective tissue forming the lateral vesical pedicle containing blood vessels and nerves to the bladder. The open end of the ring easily pierced this delicate tissue with minimal trauma. The ring was twisted closed and consequently the abdominal incision was closed in two layers with absorbable suture. The operation was performed under sterile conditions, usually in 10 min or less. In this manner 10 animals were obstructed for a period of 4 weeks, 10 for 8 weeks, and 10 served as controls.

\section{Urodynamic Investigation}

All animals underwent cystometry under urethane anesthesia according to the method we have described previously [Mostwin et al., 1991; Karim et al., 1990]. Four or eight weeks following initial obstruction, the animals were anaesthetized with urethane $(1 \mathrm{gm} / \mathrm{kg}$ i.p.). After $30-45 \mathrm{~min}$ the distended bladder could be felt through the abdominal wall. If not, a 25-gauge needle was used to locate the bladder and fill it with $2-3 \mathrm{ml} 0.9 \%$ saline by syringe until it was palpable. Two 24 -gauge $1.6-\mathrm{cm}$ pediatric angiocatheters were inserted percutaneously into the bladder. One was connected to a continuous infusion pump (Harvard Bioscience, South Natick, MA), the 
other to a pressure transducer amplified and displayed onto moving tracer paper (initially LifeTech, Houston, TX, and later Harvard Bioscience and Gould, Cleveland, $\mathrm{OH})$. The signal was also digitized and stored on magnetic disc for subsequent analysis (IBM XT, Data Translation 2801 A/D convertor, Marlboro, MA, CODAS Waveform scroller, Datac, Inc., Akron, $\mathrm{OH}$ ). The urethra was neither instrumented nor catheterized. The bladder was filled at a continuous rate of $0.82 \mathrm{ml} / \mathrm{min}$ with $0.9 \% \mathrm{NaCl}$ at $20^{\circ} \mathrm{C}$. The animal was observed for signs of voiding or leakage of solution per urethram. The volume voided was collected in a graduated pipette connected to a pressure transducer for recording of voided volume. At least 10 voiding cycles were observed in each animal. We examined the following urodynamic parameters in the voiding cycles of all animals: resting bladder pressure (RBP), the intravesical pressure at the beginning of each new voiding cycle; end filling pressure (EFP), the maximum pressure measured before active bladder contraction was seen; peak voiding pressure (PVP); compliance (CMP), the ratio of the infused volume per cycle to EFP-RBP; residual urine (PVR); voided volume (VV); and bladder capacity (CAP). After examination of the cystometric tracings, animals were assigned to one of five urodynamic categories, based on the appearance of the tracing. The five categories: normal, high pressure voiding, unstable, low compliance, and decompensated are further defined in the Results section. At the end of this procedure, the animal was sacrificed with $\mathrm{CO}_{2}$ inhalation, the bladder and urinary tract were examined grossly, and the bladder was removed by dividing at the bladder neck. The bladders were separated from associated structures, excessive fat, and connective tissue, blotted once on each side to absorb surface moisture, then weighed on an electronic scale. Bladder weight and urodynamic parameters were tabulated and compared to normals by nonpaired t-test.

\section{Examination of In Vitro Contraction}

Smooth muscle bundles were identified in the muscularis of the urinary bladder of each animal. From these bundles six $0.5 \mathrm{~mm} \times 8( \pm 1) \mathrm{mm}$ strips (wet weight was determined following experiment) were cut longitudinally. Special care was taken so that strips had similar lengths. Each of the 6 strips was suspended at $0.5 \mathrm{~g}$ tension in an organ bath (vol. $0.2 \mathrm{ml}$ ) modified for isometric tension recording and electrical stimulation by paired platinum ring electrodes. The strips were perfused continuously in one direction at a constant rate with a modified Krebs solution containing (mM): $\mathrm{NaCl} 120 ; \mathrm{KCl} 5.9 ; \mathrm{NaHCO} 3$ 15.4; $\mathrm{MgCl} 2$ 1.2; $\mathrm{NaH} 2 \mathrm{PO} 41.0 ; \mathrm{CaCl} 2$ 2.5; glucose 11 , equilibrated with $97 \% 02 / 3 \% \mathrm{CO}_{2}, \mathrm{pH} 7.4$ at $36^{\circ} \mathrm{C}$. Following equilibration for $1 \mathrm{hr}$, all 6 tissue strips were simultaneously exposed to the following stimuli, separated by additional equilibration periods of $10 \mathrm{~min}$ :

\footnotetext{
1. Field stimulation of intramural nerves $(0.050 \mathrm{msec}, 50 \mathrm{~V}, 128 \mathrm{~Hz}$ trains for $5 \mathrm{sec})$.

2. Direct electrical muscle stimulation $(5.0 \mathrm{msec}, 5 \mathrm{~V}, 128 \mathrm{~Hz}$, for $5 \mathrm{sec})$.

3. Carbachol $10 \mathrm{mM}(12 \mathrm{sec})$ dissolved in Krebs solution.

4. Potassium rich solution, $\mathrm{KCL}$ replaced $\mathrm{NaCl}$, so that the potassium concentration totalled $142 \mathrm{mM}$ in Krebs solution $(60 \mathrm{sec})$.
}

Following the in vitro contractility studies, each strip was removed, blotted once, and weighed. 


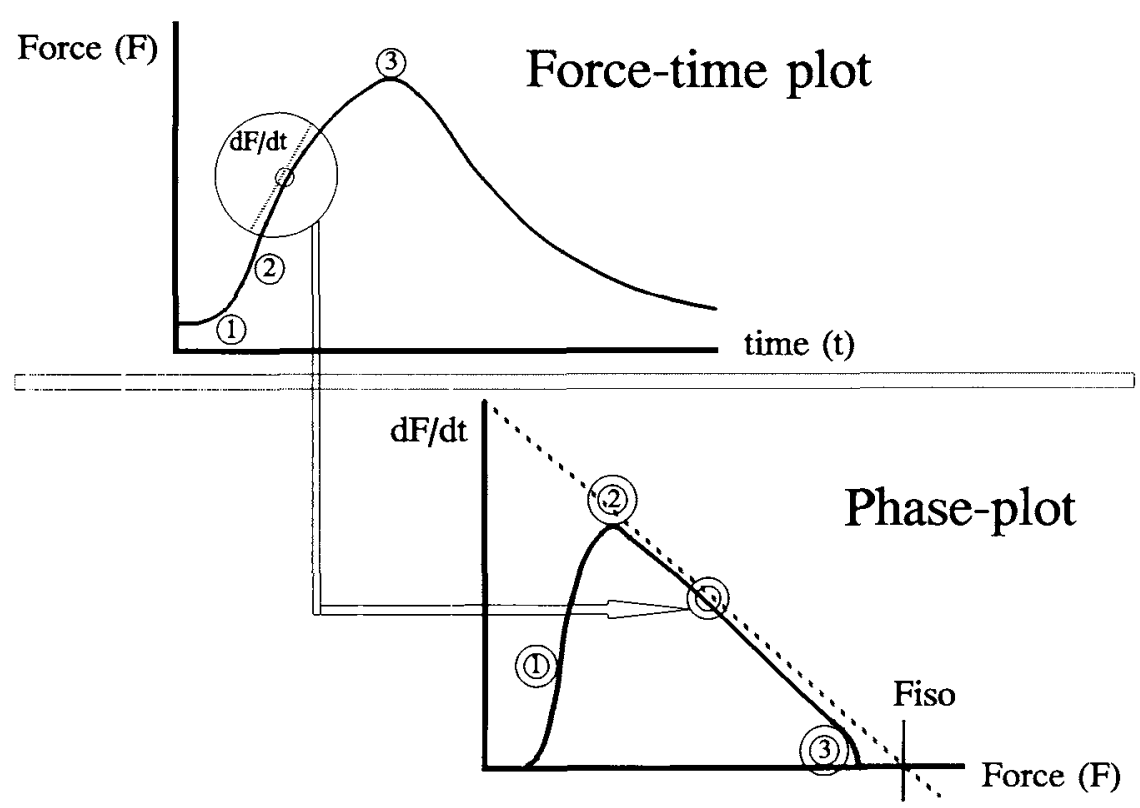

Fig. 1. Phase plot, a plot of the rate of change of force $(\mathrm{dF} / \mathrm{dt})$ as a function of the force $(F)$, was derived from the force-time plot as indicated. The numbers 1,2 , and 3 in the phase plot correspond to points 1 , 2 , and 3 in the force-time plot, from which they were calculated. The straight line portion of the phase-plot curve can be extrapolated to the F axis to yield the parameter Fiso; the negative reciprocal value of the slope is parameter $\mathrm{C}$.

\section{Calculation of Force Development Parameters}

The isometric tension transducers were connected to an analog/digital converter. Waveforms from each of the 6 strips were sampled per computer in Baltimore at $10 \mathrm{~Hz}$ and stored as electronic files. These files were sent by electronic telecommunication (BITNET) to Rotterdam for phase plot analysis. The phase plot curves and parameters were sent back to Baltimore as electronic files. The average of the 6 strips from each animal was calculated and correlated with bladder weight and urodynamic category. Statistical significance was tested using Student's t-test (Statgraphics, Manugistics, Inc., Cambridge, MD).

\section{Phase Plot Analysis (Fig. 1)}

Phase plot analysis was performed by calculating instantaneous $\mathrm{dF} / \mathrm{dt}(\mathrm{t})$ (time derivative of force $F$ : the rate of force development) and displaying $\mathrm{dF} / \mathrm{dt}(\mathrm{F})$ (time derivative of force $\mathrm{dF} / \mathrm{dt}$ plotted against the force $\mathrm{F}$ itself) [Van Mastrigt et al., 1986; Van Koeveringe and Van Mastrigt, 1991]. The straight line portion of this curve was extrapolated to the $\mathrm{dF} / \mathrm{dt}$ and $\mathrm{F}$ intercepts yielding two parameters of force development. Fiso: The value of $\mathrm{F}$ at $\mathrm{dF} / \mathrm{dt}=0$, the extrapolated theoretical maximum isometric force which the tissue can generate in response to a stimulus. Fiso indicates the maximum number of contractile muscle units. $C$ : The limiting rate constant of excitation-contraction coupling. It indicates the recruitment rate of contracting units 
TABLE I. Force Development Parameters in Normal and Obstructed Bladder Muscle in Response to Electrical and Pharmacological Stimulation ${ }^{\dagger}$

\begin{tabular}{lccc}
\hline & $\begin{array}{c}\text { No obstruction } \\
(\mathrm{N}=10)\end{array}$ & $\begin{array}{c}4 \text { wks obstruction } \\
(\mathrm{N}=10)\end{array}$ & $\begin{array}{c}8 \text { wks obstruction } \\
(\mathrm{N}=10)\end{array}$ \\
\hline Stimulus & Fiso $(\mathrm{mN} / \mathrm{mg})$ & Fiso $(\mathrm{mN} / \mathrm{mg})$ & Fiso $(\mathrm{mN} / \mathrm{mg})$ \\
Nerve (field) & $6.50 \pm 0.69$ & $4.06 \pm 0.69^{*}$ & $3.87 \pm 1.00^{*}$ \\
Muscle (direct) & $5.85 \pm 0.50$ & $4.52 \pm 0.59$ & $3.93 \pm 1.01$ \\
Carbachol & $5.96 \pm 0.75$ & $7.00 \pm 0.37$ & $4.68 \pm 0.75$ \\
High-potassium & $9.24 \pm 0.85$ & $7.67 \pm 0.48$ & $6.23 \pm 1.43$ \\
Stimulus & $\mathrm{C}(\mathrm{sec})$ & $\mathrm{C}(\mathrm{sec})$ & $\mathrm{C}(\mathrm{sec})$ \\
Nerve (field) & $0.74 \pm 0.04$ & $0.85 \pm 0.09$ & $0.86 \pm 0.07$ \\
Muscle (direct) & $0.74 \pm 0.04$ & $0.93 \pm 0.15$ & $1.07 \pm 0.14$ \\
Carbachol & $5.12 \pm 0.70$ & $10.26 \pm 1.88$ & $6.86 \pm 0.83$ \\
High-potassium & $13.73 \pm 1.13$ & $16.91 \pm 1.24$ & $12.95 \pm 1.62$ \\
\hline
\end{tabular}

${ }^{\dagger}$ Values reported are for Fiso (normalized by weight; see Materials and Methods) and for C (unnormalized). Values are mean \pm SEM for electrically (nerve and muscle specific), carbachol, and potassium stimulated contractions in normal control and in 4 and 8 weeks obstructed bladders.

$* P \leq 0.05$.

and is the negative reciprocal value of the slope of the fitted straight line. The values of the force development parameters Fiso and $C$ were calculated for every strip, 6 strips were obtained from each animal. To correct for differences in cross-sectional area, measured forces are generally expressed in terms of stress, i.e., force normalized by cross-sectional area. As in our case all strips in all series were similar in length, Fiso values could be normalized by dividing by strip weight. $\mathrm{C}$ was independent of specimen weight and was not adjusted. For each animal an average parameter value for the 6 strips was calculated per stimulus. Consequently, a mean Fiso and $C$ was calculated for one stimulus either in a 4 or 8 weeks obstructed group or in one of the five urodynamic categories or in the control group.

\section{RESULTS}

All animals underwent successful partial surgical obstruction of the urethra and gained weight at rates similar to controls. Histological data on a limited number of strips showed that these consisted of purely muscle tissue with a few small connective tissue sheaths.

\section{Changes in Contractility Parameters After 4 and 8 Weeks Obstruction}

The average phase plot parameter values calculated for 4 and 8 weeks obstructed muscle strips are presented in tabular form in Table I. In Figures 2 and 3, the values are displayed in histograms. It can be seen that following 8 weeks of obstruction, the value of phase plot parameter Fiso (indicative of the maximum number of contractile muscle units) in response to field stimulation specific for nerves was reduced to $60 \%$ $(P<0.05)$ and in response to carbachol was reduced to $77 \%(P=0.2)$ of the control response. Values for the parameter $\mathrm{C}$, the inverse of the slope of the phase plot (indicative of unit recruitment during force development) were unchanged for all forms of stimulation. The parameter Fiso for direct muscle stimulation was reduced to $68 \%$ of the control response, but this result was not significant $(P=0.10)$. 


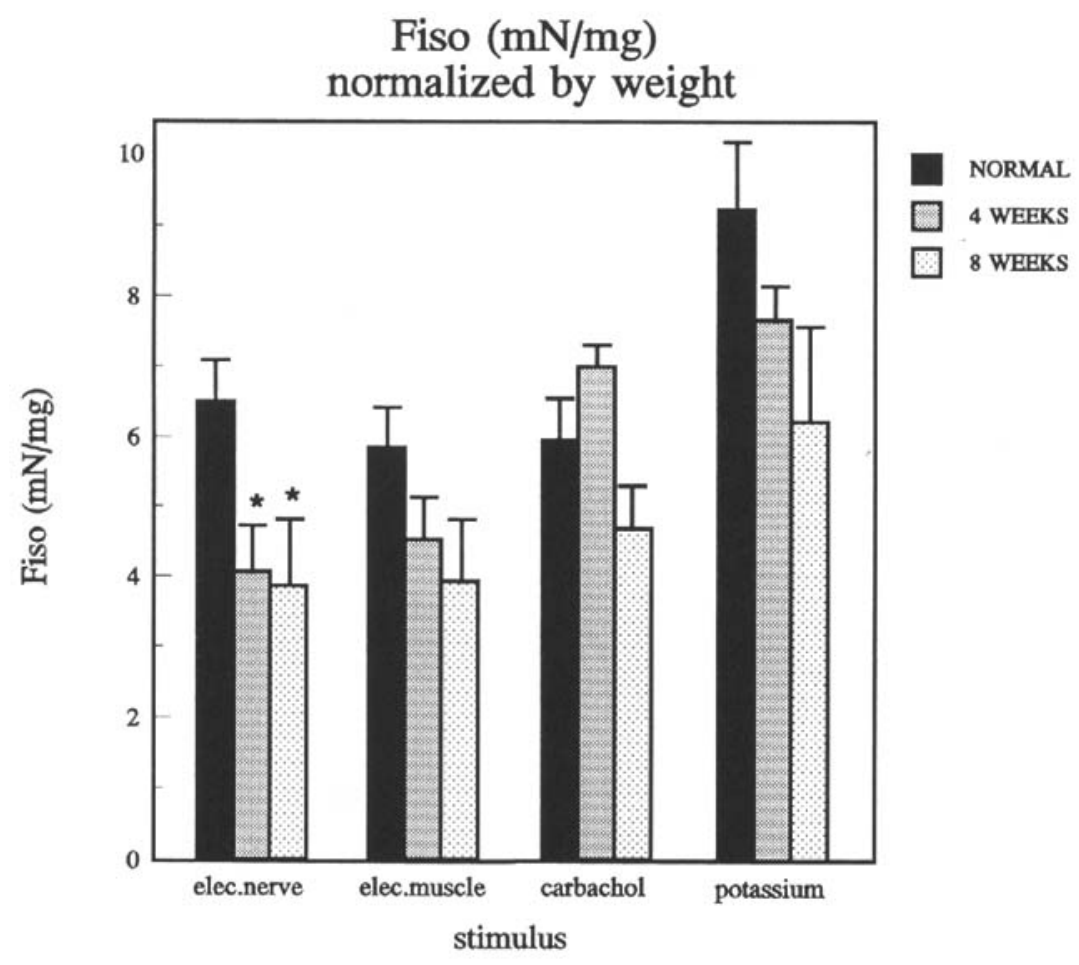

Fig. 2. Mean \pm SEM for Fiso, normalized by weight (all strips in all series had a similar length, see Materials and Methods), for electrically (elec.; nerve and muscle specific), carbachol, and potassium stimulated contractions in normal control and in 4 and 8 weeks obstructed bladders. *A significant reduction compared to the normal controls is shown in response to nerve stimulation after $4(P<0.05)$ and $8(P \leq 0.05)$ weeks obstruction.

\section{Relationship of Changes in Contractility and Urodynamic Parameters}

The urodynamic study was successfully performed on 17/20 animals and 9/10 controls. These results have been previously presented in detail [Karim et al., 1990] and form the basis of a separate report [Mostwin et al., 1991]. Normal animals showed stable and compliant cystometry curves, with an occasional small amplitude precontraction. Average weight of normal bladders was $0.54 \pm 0.05 \mathrm{~g}(\mathrm{~N}=9)$.

Four urodynamic abnormalities were identified in the obstructed animals:

1. High pressure: a markedly higher ( $>$ twofold) voiding pressure than in the normal or in any of the other categories in which instability, compliance change, or decompensation dominated. Average bladder weight in this group was $0.85 \pm$ $0.07 \mathrm{~g}(\mathrm{~N}=6)$.

2. Unstable: resembled the cystometrograms of human patients with clinically unstable bladders which show multiple unstable contractions superimposed on the filling cystometry. Bladder weight was $1.17 \pm 0.15 \mathrm{~g}(\mathrm{~N}=5)$.

3. Low compliance: showed high endfilling pressures but also generated sufficient active contraction at capacity to at least partially empty the bladder so that a voiding cycle resulted. Bladder weight was $0.76 \pm 0.05 \mathrm{~g}(\mathrm{~N}=2)$. 


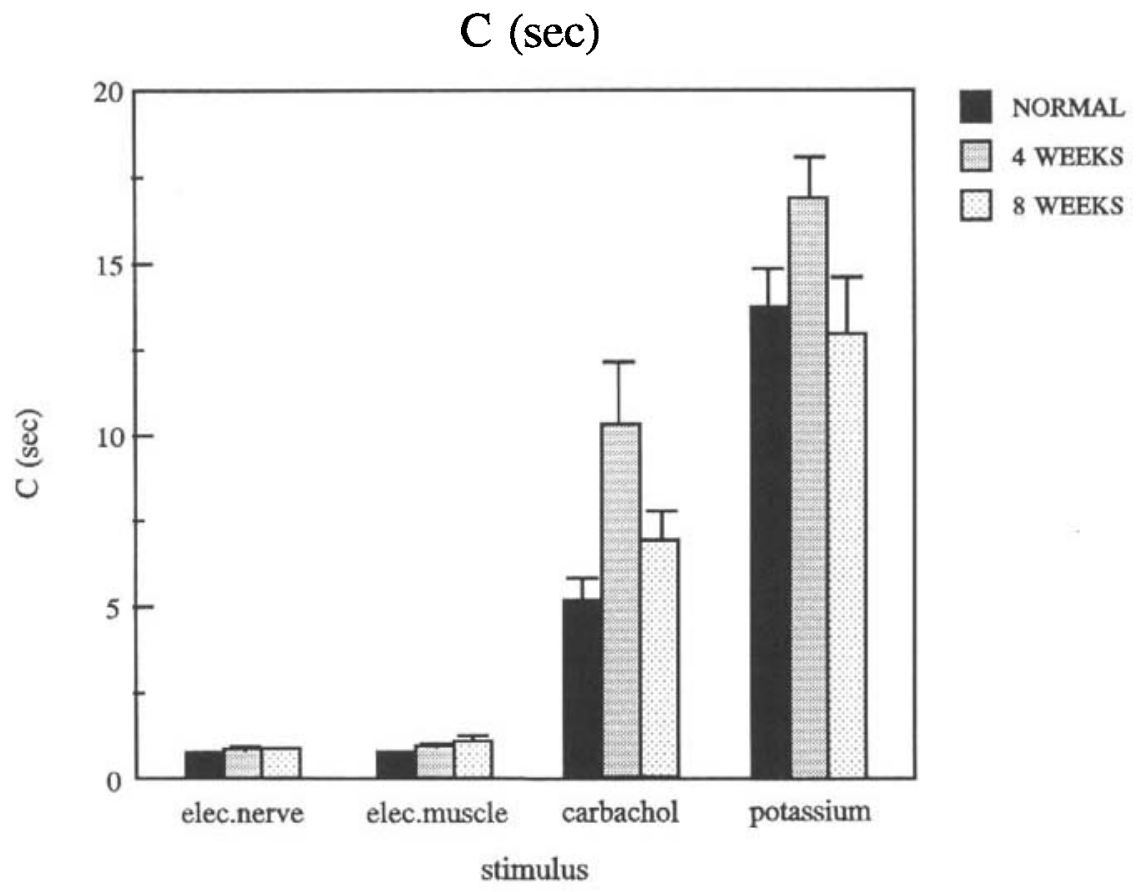

Fig. 3. The recruitment rate of contractile units (parameter $\mathrm{C}$ ) in guinea pig bladder muscle. Mean \pm SEM for electrically (elec.; nerve and muscle specific), carbachol, and potassium stimulated contractions in normal control and in 4 and 8 weeks obstructed bladders.

4. Decompensated: showed no evidence of an active contraction, filled to a high endfilling pressure, then overflowed passively at capacity with a large postvoid residual volume. Bladder weight was $1.47 \pm 0.11 \mathrm{~g}(\mathrm{~N}=4)$.

The force development parameters in response to four stimuli (field stimulation of nerves, direct muscle stimulation, carbachol, and high potassium) for all animals in each of the four urodynamic categories and in the control group are displayed in Table II. The values are displayed in histograms in Figures 4 and 5.

A significant reduction in Fiso value was found in response to direct nerve stimulation in unstable and in decompensated bladders to $35 \%(P<0.01)$ and to $45 \%$ $(P<0.01)$ of the control response. In response to direct muscle stimulation the Fiso value was reduced to $56 \%(P<0.05)$ of the control response in the decompensated group and to $53 \%(P<0.05)$ of the control response in the unstable group. In response to carbachol no reduction of Fiso could be shown in either of these two groups. In response to high-potassium stimulus Fiso showed a reduction in the unstable group to $67 \%(P<0.05)$ of the control response. In $\mathrm{C}$ values also in the different categories of in vivo urodynamic dysfunction no significant change was seen when compared with the normal controls, except for the $\mathrm{C}$ values of direct muscle stimuli in the decompensated group.

Our results did not show a gradual increase of changes in either urodynamic parameters or in muscle contractility parameters between 4 and 8 weeks of obstruction. 
TABLE II. Average Bladder Weight and Force Development Parameters of Normal and Obstructed Bladders in Response to Electrical and Pharmacological Stimuli According to Category of Urodynamic Dysfunction ${ }^{\dagger}$

\begin{tabular}{lccccc}
\hline & $\begin{array}{c}\text { Normal } \\
(\mathrm{N}=9)\end{array}$ & $\begin{array}{c}\text { High pressure } \\
(\mathrm{N}=5)\end{array}$ & $\begin{array}{c}\text { Unstable } \\
(\mathrm{N}=6)\end{array}$ & $\begin{array}{c}\text { Low compliance } \\
(\mathrm{N}=2)\end{array}$ & $\begin{array}{c}\text { Decompensated } \\
(\mathrm{N}=4)\end{array}$ \\
\hline $\begin{array}{l}\text { Average bladder } \\
\text { weight (g) }\end{array}$ & $0.54 \pm 0.05$ & $0.85 \pm 0.07$ & $1.17 \pm 0.15$ & $0.76 \pm 0.05$ & $1.47 \pm 0.11$ \\
Stimulus & Fiso (mN/mg) & Fiso $(\mathrm{mN} / \mathrm{mg})$ & Fiso $(\mathrm{mN} / \mathrm{mg})$ & Fiso $(\mathrm{mN} / \mathrm{mg})$ & Fiso $(\mathrm{mN} / \mathrm{mg})$ \\
$\quad$ Nerve (field) & $6.55 \pm 0.77$ & $5.83 \pm 1.49$ & $2.97 \pm 0.56^{* *}$ & $3.28 \pm 0.48$ & $2.31 \pm 0.72^{* *}$ \\
Muscle (direct) & $5.71 \pm 0.53$ & $6.15 \pm 1.83$ & $3.03 \pm 0.41^{* *}$ & $3.08 \pm 0.26$ & $3.22 \pm 0.87^{*}$ \\
Carbachol & $6.01 \pm 0.83$ & $5.82 \pm 1.22$ & $6.17 \pm 0.80$ & $5.50 \pm 1.40$ & $5.43 \pm 1.28$ \\
High-potassium & $8.92 \pm 0.88$ & $8.50 \pm 2.42$ & $5.98 \pm 0.85^{*}$ & $5.64 \pm 0.35$ & $5.89 \pm 1.21$ \\
Stimulus & $\mathrm{C}(\mathrm{sec})$ & $\mathrm{C}(\mathrm{sec})$ & $\mathrm{C}(\mathrm{sec})$ & $\mathrm{C}(\mathrm{sec})$ & $\mathrm{C}(\mathrm{sec})$ \\
$\quad$ Nerve (field) & $0.73 \pm 0.05$ & $0.81 \pm 0.04$ & $0.90 \pm 0.14$ & $0.56 \pm 0.06$ & $1.01 \pm 0.11$ \\
Muscle (direct) & $0.74 \pm 0.03$ & $0.86 \pm 0.08$ & $0.86 \pm 0.12$ & $0.63 \pm 0.16$ & $1.76 \pm 0.63^{*}$ \\
Carbachol & $4.92 \pm 0.74$ & $6.81 \pm 1.23$ & $11.67 \pm 1.96$ & $11.52 \pm 2.71$ & $7.26 \pm 2.65$ \\
High-potassium & $13.01 \pm 1.00$ & $16.08 \pm 1.38$ & $14.95 \pm 2.86$ & $12.98 \pm 0.70$ & $13.33 \pm 2.29$ \\
\hline
\end{tabular}

${ }^{\dagger}$ Values reported are for Fiso (normalized by weight; see Materials and Methods) and for C (unnormalized). Values are mean \pm SEM for electrically (nerve and muscle specific), carbachol, and potassium stimulated contractions in normal control, high pressure, unstable, low compliance, and decompensated categories of obstruction.

$* P<0.05$.

$* * P<0.01$

\section{DISCUSSION}

In this study, in vivo and in vitro bladder function was studied after a prolonged time of urethral obstruction in a guinea pig model. More specifically, parameters of in vitro isometric force development were related to four in vivo identified patterns [Mostwin et al., 1991] of abnormal bladder function secondary to the obstruction, i.e., patterns showing high pressure voiding, instability, low compliance, and decompensation.

When bladder weight alone was observed, the weight increased when advancing from normal via high pressure voiding, and from unstable to decompensated bladders. This observation suggests that a decreasing in vivo bladder function and an increase in bladder weight were associated.

In order to quantify bladder function in vitro, the time course of force development in the muscle strips was analysed. Previous research on bladder smooth muscle has shown that it is not possible to perform reproducible measurements at $\mathrm{L}_{\text {max }}$, the length of the strip at which maximum force can be generated [Griffiths et al., 1979]. Active measurements were performed well below $\mathrm{L}_{\max }$, to prevent continuous passive lengthening. Obstructed guinea pig bladder showed a significant reduction in the force development parameter associated with the maximum number of contracting muscle units (Fiso, Fig. 2). The parameter $\mathrm{C}$, indicative of the recruitment rate of contractile units during a contraction, did not show a significant change (Fig. 3). Figure 6 illustrates the resulting parallel downward shift in the straight line part of the phase plot as it occurred with obstruction. In the above definition of Fiso and C, "contractile unit" can refer to either a cell or a contractile structure within a cell (e.g., crossbridges). Previous research [Mattiasson and Uvelius, 1982; Lindner et 


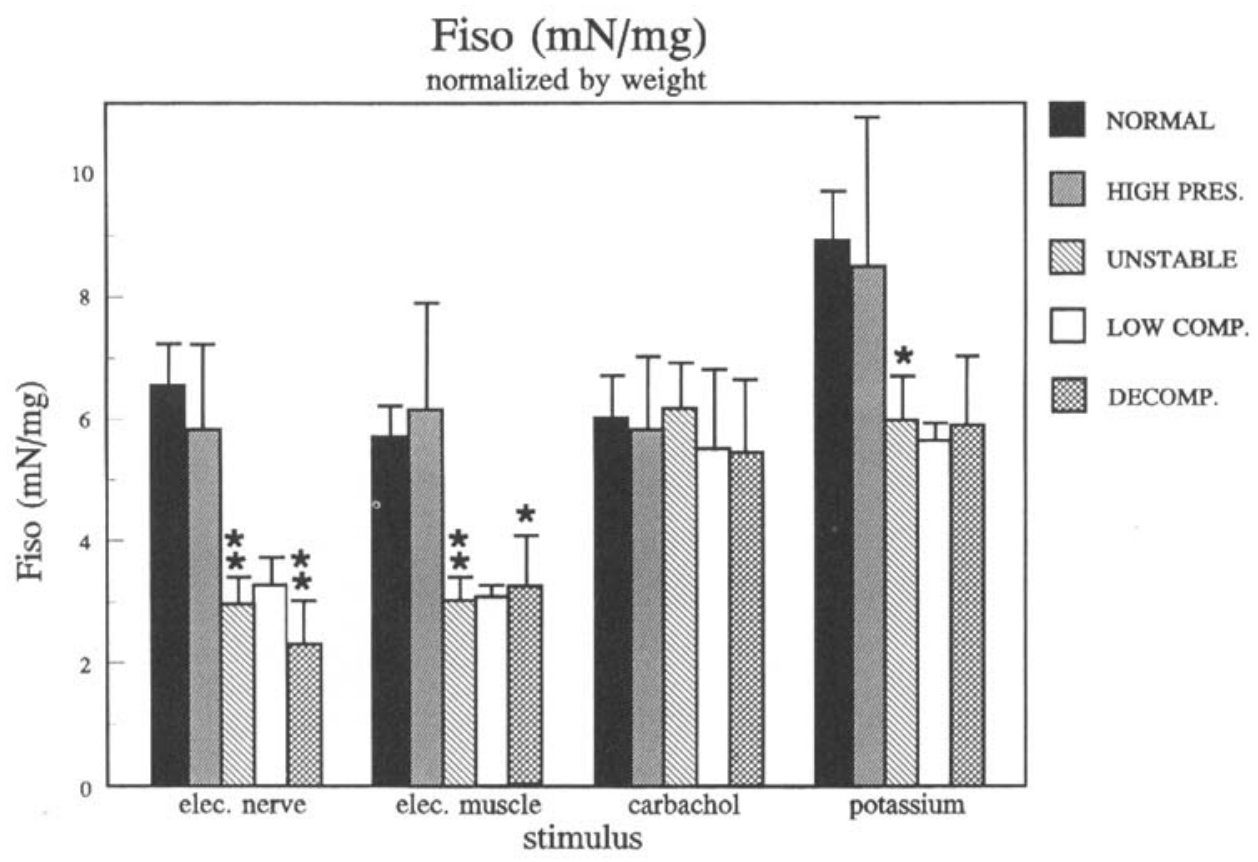

Fig. 4. Mean \pm SEM for Fiso, normalized by weight (all strips in all series had a similar length, see Materials and Methods), for electrically (elec.; nerve and muscle specific), carbachol, and potassium stimulated contractions in normal control, and the high pressure (PRES.), unstable, low compliance (COMP.), and decompensated (DECOMP.) categories of obstruction. In the unstable group a significant reduction compared to the normal controls is shown in response to nerve $(* * P<0.01)$, muscle $(* * P<0.01)$, and potassium $(* P<0.05)$ stimulation. In the decompensated group the reduction was significant in response to nerve $(* * P<0.01)$ and muscle $(* P<0.05)$ stimulation.

al., 1988] has not shown a decrease in DNA concentration in obstructed bladder muscle tissue so that a decrease in Fiso cannot be explained by a decay in the number of cells per gram of tissue. This favours the alternative hypothesis of contractile unit meaning an intracellular contractile structure.

No gradual change in in vitro force development parameters in response to obstruction could be demonstrated in the sense that the changes observed after 4 and 8 weeks of obstruction were not significantly different. Probably bladders did not all follow a sequence of changes at the same pace, as a result of either a different responsiveness of the bladder in different animals or spontaneous differences in the degree of obstruction in the animals.

In Figure 4 it appears that the force development parameter Fiso shows two distinctly different values. Normal bladders and bladders with high pressure voiding showed high Fiso values. Unstable and decompensated bladders showed Fiso values at a lower level. As bladders with high pressure voiding alone showed neither significant changes in the force development parameters nor in bladder weight, high pressure voiding is likely to be the least severe grade of dysfunction. High pressure voiding may just be secondary to a lower flow rate, causing the bladder to operate at another point on the bladder output relation, which implies an unchanged contractility. Thus high pressure voiding represents an initial physiological response to ob- 


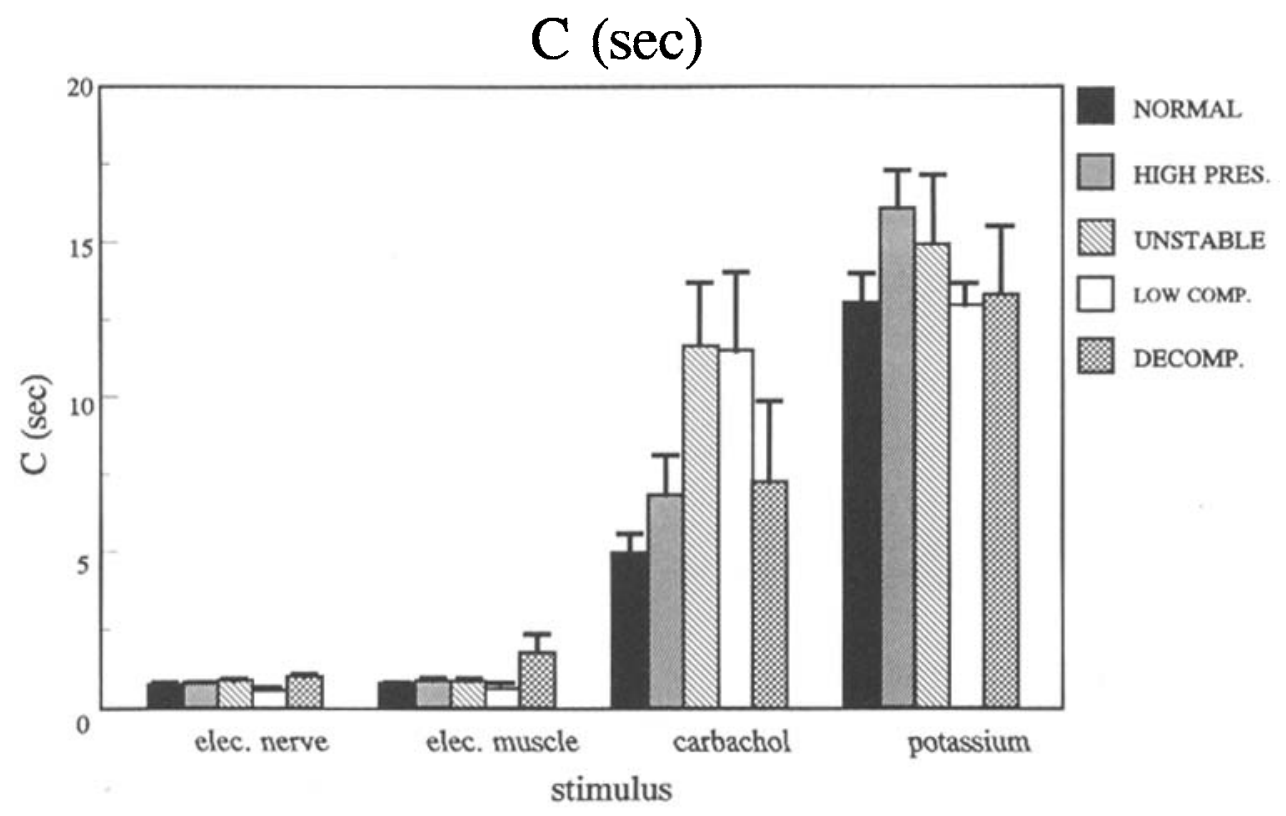

Fig. 5. The recruitment rate of contractile units (parameter $\mathrm{C}$ ) in guinea pig bladder muscle. Mean \pm SEM for electrically (elec.; nerve and muscle specific), carbachol, and potassium stimulated contractions in normal control, high pressure (PRES.), unstable, low compliance (COMP.), and decompensated (DECOMP.) categories of obstruction.

struction. However the unstable bladders, which represent the probable next stage of dysfunction, showed a significant reduction in the values of the force development parameter Fiso in association with a significant bladder weight gain. This indicates that instability represents a more advanced form of response to obstruction. The decompensated bladders showed significant changes in parameter values of Fiso, similar to changes seen in the unstable group, especially in response to field stimulation of nerves and to direct muscle stimulation. The force development parameters showed occasionally variable responses, such as Fiso in response to carbachol and force development rate constant $\mathrm{C}$ in response to direct muscle stimulation. No obvious explanation could be given for this effect. Finally the decompensated bladders weighed significantly more than bladders in any other category, which suggests that decompensation is the final step in the decreasing bladder function. Due to a small sample size $(\mathrm{N}=2)$ no conclusions could be drawn for the low compliance category, however the reduction of Fiso in this group suggests that this form of dysfunction has characteristics similar to those of instability or decompensation, although the relatively low bladder weight militates against this hypothesis.

The decline in Fiso with increasing bladder weight suggests several possible explanations. An increase in the amount of connective tissue might result in a relative decrease of the number of contractile muscle units (crossbridges) per gram of bladder tissue. As a consequence the DNA concentration per gram of tissue would decrease, which is contradicted by previous studies on obstructed bladder tissue [Mattiasson and Uvelius, 1982; Lindner et al., 1988], thus impairing the likeliness of this expla- 


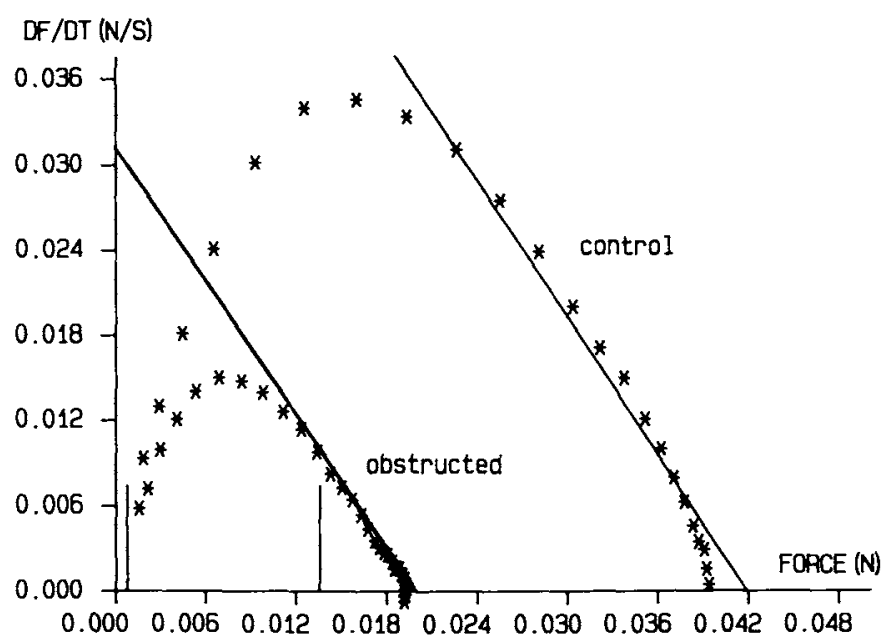

Fig. 6. Phase plots ([dF/dt (F)] derived from bladder strip contractions of a control animal and of an obstructed animal. These plots typically illustrate the parallel shift in the straight line part occurring with obstruction.

nation. A reduction in Fiso might also be explained by the hypothesis that fewer units can be stimulated to the threshold where contraction occurs, i.e., obstruction affecting the conversion of chemical into mechanical energy. Another hypothesis would be that the average muscle cell size increases, without a consequent increase in the number of contractile units per cell, leaving a smaller number of contractile units (crossbridges) per gram of tissue. This hypothesis is supported by a previously described lower actin and myosin content of obstructed muscle tissue [Uvelius et al., 1989]. Analogous to the findings of Arner et al. [1990], an increase in cell size might also cause a different orientation of crossbridges so that less force is generated in the direction in which force is measured. Considerably more data will be needed in order to fully explain the decrease in Fiso associated with bladder weight gain.

In Figures 2 and 4, besides a slightly better statistical significance, nerve stimulation did not seem to be more affected by obstruction than direct muscle stimulation. As the latter is a more direct form of stimulation as opposed to nerve stimulation, the results indicate that the described effects of obstruction resulted mostly from muscle change.

In pig bladders the value of the parameter $C$ has been shown to be related to an intracellular process [Van Koeveringe and Van Mastrigt, 1991], i.e., the influx of extracellular calcium. As $\mathrm{C}$ showed similar values when the bladder was obstructed in this study, this process was apparently not affected by obstruction. Changes in presumably faster contractile processes such as crossbridge attachment and cycling could not be detected because the slower influx of extracellular calcium is the rate limiting step.

It is concluded that the parameter that characterizes maximal in vitro force development is impaired in obstructed guinea pigs with unstable and decompensated bladders and not in animals characterized by high pressure voiding alone. On the basis of increased bladder weight, the former dysfunctions can be interpreted as more 
advanced stages. There was no change in the rate of isometric force development in vitro in the obstructed animals. Generally, bladder dysfunction and impaired in vitro force development are associated, and appear to be greater (more advanced) as bladder weight increases.

\section{REFERENCES}

Arner A, Malmquist U, Uvelius B (1990): Metabolism and force in hypertrophic smooth muscle from rat urinary bladder. Am J Physiol (Cell Physiol 27) 258:C923_C932.

Blaivas JG (1988): Pathophysiology and differential diagnosis of benign prostatic hypertrophy. Urology 32(Suppl 6):5-11.

Brading AF, Sibley GNA (1983): A superfusion apparatus to study field stimulation of smooth muscle from mammalian urinary bladder. J Physiol 334:1112P.

Coolsaet B, Blok C (1986): Detrusor properties related to prostatism. Neurourol Urodyn 5:435-447.

Griffiths DJ, Van Mastrigt R, Van Duyl WA, Coolsaet BLRA (1979): Active mechanical properties of the smooth muscle of the urinary bladder. Med Biol Eng Comput 17:281-290.

Karim OMA, Van Koeveringe GA, Mostwin JL (1990): Development of abnormal voiding patterns following partial urethral obstruction of the guinea pig urethra. J Urol 143:355A.

Lindner P, Mattiasson A, Persson L, Uvelius B (1988): Reversability of detrusor hypertrophy and hyperplasia after removal of infravesical outflow obstruction in the rat. J Urol 140:642-646.

Malkowicz SB, Wein AJ, Elbadawi A, Van Arsdalen K, Ruggieri MR, Levin RM (1986): Acute biochemical and functional alterations in the partially obstructed urinary bladder. J Urol 136:13241329.

Mattiasson A, Uvelius B (1982): Changes in contractile properties in hypertrophic rat urinary bladder. $\mathbf{J}$ Urol 128:1340-1342.

Mostwin JL, Brooks EL (1989): A new guinea pig model of urethral obstruction. J Urol 141:334A.

Mostwin JL, Karim OMA, Van Koeveringe GA, Brooks EL (1991): The guinea pig as a model of gradual urethral obstruction. J Urol 145:854-858.

Uvelius B, Arner A, Malmqvist U (1989): Contractile and cytoskeletal proteins in detrusor muscle from obstructed rat and human bladder. Neurourol Urodyn 8:396--398.

Van Koeveringe GA, Van Mastrigt R (1991): Excitatory pathways in smooth muscle investigated by phaseplot analysis of isometric force development. Am J Physiol 261 (Regul Integ Comp Physiol 30):R138-144.

Van Mastrigt R, Glerum JJ (1985): Electrical stimulation of smooth muscle strips from the urinary bladder of the pig. J Biomed Eng 7:2-8.

Van Mastrigt R, Koopal JWB, Hak J, Van de Wetering J (1986): Modeling the contractility of urinary bladder smooth muscle using isometric contractions. Am J Physiol 251:R978-983.

\section{EDITORIAL COMMENT}

\section{EFFECT OF PARTIAL URETHRAL OBSTRUCTION ON FORCE DEVELOPMENT OF THE GUINEA PIG BLADDER}

The knowledge of pathophysiologic changes of lower and upper tract becomes increasingly important because clinicians become aware of the fact that lower tract symptoms in the aging male are multifactorial. Obstruction is only one of the potential factors. Recent information indicates that a slightly or mildly obstructed bladder not necessarily progresses and threatens vital functions, neither interferes with the quality of life. Obstruction will probably become even less important, the better we understand its evolution and pathophysiology. The paper by Van Koeveringe et al. deals with several important aspects of obstruction: modelling and secondary bladder storage and evacuation dysfunction. 